\title{
Beden Değeri Ölçeği-2’nin (BDÖ-2) Türkçe Adaptasyonu: Geçerlik ve Güvenirlik Çalışması
}

\section{Adaptation of The Body Appreciation Scale-2 (BAS-2) to Turkish: A Validity and Reliability Study}

\begin{abstract}
Vesile OKTAN*, Ezgi SAYLAN**
Öz: Bu çalışmanın amacı, Tylka ve Wood-Barcalow (2015) tarafından bireylerin kendi bedenlerine yönelik ne derece olumlu düşünceleri olduğunu ve bu düşüncelere saygı duyup duymadıklarını değerlendirmek amacıyla geliştirilmiş olan Beden Değeri Ölçeği-2 (BAS-2)'nin faktör yapısını incelemektir. Beden Değeri Ölçeği-2, 5'li Likert türü bir ölçme aracı olup 10 maddeden oluşmaktadır. Beden Değeri Ölçeği-2'nin faktör yapısı, 15-24 yaş aralığındaki kadın ve erkek bireylerden oluşan 649 kişilik çalışma grubu üzerinde incelenmiştir. Ölçeğin faktör yapısını ortaya koymak üzere açımlayıcı ve doğrulayıcı faktör analizi yapılmıştır. Geçerlik ve güvenirlik analizleri için IBM SPSS Statistics v20.0 ve Lisrel 8.80 programları kullanılmıştır. Güvenirlik analizlerinde Cronbach alfa iç tutarlık katsayısı tekniğinden faydalanılmıştır ve ölçeğin genel güvenirliği 90 olarak bulunmuştur. Faktör analizi sonuçları ölçeğin özgün formunda olduğu gibi tek boyutlu bir yapıda olduğunu ortaya koymuştur. Analiz sonuçları, Beden Değeri Ölçeği-2'nin Türk genç ve genç yetişkinler üzerinde yeterli düzeyde geçerlik ve güvenirlik değerlerine sahip olduğunu ve bireylerin bedenlerine yönelik algılarını değerlendirmede geçerli ve güvenilir bir araç olarak kullanılabileceğini göstermiştir.
\end{abstract}

Anahtar Kelimeler: Beden değeri, ölçek, geçerlik, güvenirlik

Abstract: The aim of this study is to examine the factor structure of the Body Appreciation Scale-2 (BAS2), which was developed by Tylka and Wood-Barcalow (2015) in order to evaluate the positive opinions of individuals about their own bodies and whether they respect these thoughts. Body Appreciation Scale-2 is a 5-point Likert-type measuring instrument and consists of 10 items. The factor structure of the Body Appreciation Scale-2 was examined on a study group of 649 men and women aged 15-24 years. Exploratory and confirmatory factor analyzes were performed to reveal the factor structure of the scale. IBM SPSS Statistics v20.0 and Lisrel 8.80 programs were used for validity and reliability analyzes. The results of the factor analysis revealed that the scale had a one-dimensional structure as in its original form. Cronbach's alpha internal consistency coefficient technique was used in the reliability analyzes and the overall reliability of the scale was found to be .90 . The results of the analysis showed that the Body Appreciation Scale-2 had sufficient validity and reliability Appreciations on Turkish young and young adults and could be used as a valid and reliable tool for assessing the perceptions of individuals on their bodies.

Keywords: Body appreciation, scale, validity, reliability

\section{Giriş}

Beden imaj1, bireyin beden memnuniyeti, beden değeri ve fiziksel durumuyla ilgili düşüncelerinin ve duygularının çok boyutlu ve karmaşık olarak tanımlanmasıdır (Cash ve Pruzinsky, 2002). Bedensel görünüm bireyin kendilik algısının önemli bir yönünü oluşturmaktadır (Dittmar, Halliwell ve Ive, 2006). Beden imaj1; beden memnuniyeti, beden değeri ve fiziksel görünüm gibi birçok bileşenden oluşmakta ve bu bileşenler pozitiften negatife doğru çeşitlilik göstermektedir. Ancak beden imajı literatürünün öncelikle bireylerin kendilerine yönelik olumsuz bir yönelimi benimsemelerinin ölçülmesine odaklandığı görülmektedir (Tylka ve Wood-Barcalow, 2015). Diğer yandan bazı araştırmacılar pozitif beden imajının yordayıcılarının ve sonuçlarının daha

\footnotetext{
* Doç. Dr. Trabzon Üniversitesi, Fatih Eğitim Fakültesi, Trabzon, Türkiye, ORCID: 0000-0001-8968-408X, e-posta: vesileoktan@gmail.com

** Yüksek lisans öğrencisi, Trabzon Üniversitesi, Fatih Eğitim Fakültesi, Trabzon, Türkiye, ORCID: 0000-0002-82557579, e-posta: ezgisaylan@gmail.com
} 
geniş bir şekilde çalışılmasının faydalı olacağını, pozitif beden imajını destekleyen faktörlerin negatif beden imajı ile mücadelede kullanılabileceğini belirtmektedirler (Williams, Cash ve Santos, 2004).

Beden imajı ile ilgili literatürde dikkat çeken bir diğer nokta ise daha çok kadınlara dönük ölçme araçlarının geliştirilmiş ve kadınlar üzerinde araştırmaların yürütülmüş olmasıdır. Özellikle kadınların toplum tarafından dayatılan güzellik algısına daha fazla maruz kalması ve medyanın etkisi buna yol açmışırı. Ancak daha sonraları birçok araştırmacı, erkeklerin de beden imajıyla ilgili endişeleri olduğunu ve bu alanda araştırmalar yapılmaya başladığını belirtmiş̧lerdir (Bergeron ve Tylka, 2007; Barlett ve Harris, 2008; Morrison, Morrison, Hopkins ve Rowan, 2004). Tylka ve Wood-Barcalow (2015) tarafından geliştirilmiş olan Beden Değeri Ölçeği-2 (The Body Appreciation Scale-2- BAS-2) hem pozitif beden değerine odaklanmaya dönük hem de kadın ve erkeklerin beden değerini ölçmeye dönük olması açısından önemli görülmüş ve Türkçe adaptasyon çalışmasının bu konuda çalışma yapan araştırmacılara katkı sağlayacağ düşünülmüştür.

BAS-2, araştırmacılar tarafından pozitif beden imajının özelliklerini, bağıntılarını ve potansiyel sonuçlarını anlamak için kullanılmıştır. BAS-2, 10 maddeden oluşan 5'li Likert tipi, ergen ve yetişkinlere uygulanan bir ölçektir. Beden değeri, uyumlu özellikler ile pozitif olarak ve ABD, İngiltere ve Avustralya dâhil olmak üzere Batı ülkelerinden gelen kadın ve erkek örneklemi arasında uyumsuz özelliklerle negatif olarak ilişkilendirilmiştir. Daha belirgin olarak beden değeri, olumlu görünüm değerlendirmesi (Avalos, Tylka ve Wood-Barcalow, 2005), beden saygısı (Avalos ve diğerleri, 2005; Swami, Stieger, Haubner ve Voracek, 2008) ve psikolojik iyi oluşun çoklu endeksleri (örneğin, benlik saygısı, iyimserlik, proaktif başa çıkma, olumlu etki, yaşam doyumu ve öz-şefkat) ile pozitif olarak ilişkilidir (Avalos ve diğerleri, 2005; Oktan ve Şahin, 2010; Tylka ve Kroon Van Diest, 2013). Beden değeri, beden memnuniyetsizliği, sosyal beden kaygısı, beden imajından kaçınma, bedenden utanma, beden gözetimi, beden kontrol davranışları ve toplumsal görünüş ideallerinin içselleştirilmesi ile negatif yönde ilişkilidir (Avalos ve diğerleri, 2005; Swami, Hwang, ve Jung, 2012; Tylka, 2013). Beden değeri aynı zamanda yeme bozukluğu belirtileri (Joiner ve Kashubeck, 1996; Tylka ve Kroon Van Diest, 2013), nevrotiklik (Swami, Hadji-Michael ve Furnham, 2008) ve uyumsuz mükemmeliyetçilik (Iannantuono ve Tylka, 2012) ile de negatif yönde ilişkilidir.

BAS-2, birçok ülkede yapı geçerliliği açısından beden değerinin değerlendirilmesinde yeterli görülmüsstür. ABD ve Avustralya'dan kadınlar ve erkekler için .90 ve üzerinde iç tutarlılık güvenilirlik katsayılarına sahip olduğu belirtilmiştir. ABD, İngiltere ve Almanya'dan üniversite ve toplum kadın ve erkek örneklemiyle ve aynı zamanda İspanya'daki ergen kadın ve erkeklerin verileri, BAS-2'nin tek boyutlu faktör yapısını, açımlayıcı ve doğrulayıcı faktör analizleri ile desteklemektedir (Tylka ve Wood-Barcalow, 2015).

Bu çalışmanın amacı, Tylka ve Wood-Barcalow (2015) tarafından geliştirilmiş olan BAS-2'nin Türk toplumu örnekleminde geçerlik ve güvenirliğini incelemektir. Çalışmada ölçeğin Türkçe formunun İngilizce özgün formuyla benzer psikometrik özelliklere sahip olduğu varsayımı sınanmıştır. Ülkemizde beden imajı ve değerini ölçmeye yönelik son derece sınırlı sayıda ölçme aracının olması çalışmanın yürütülmesi için motivasyon kaynağı olmuştur. Bu çalışmanın beden imajı ve değeri ile ilgili Türkiye literatüründe önemli bir boşluğu dolduracağı düşünülmektedir.

\section{Yöntem \\ Örneklem/çalışma grubu}

$\mathrm{Bu}$ araştırma Trabzon ilindeki Fatih Sultan Mehmet Lisesi, Avrasya Üniversitesi ve Trabzon Üniversitesi’nde öğrenim gören 649 lise ve üniversite öğrencisi üzerinde yürütülmüştür. Öğrencilerin 285'i lisede, 364'ü üniversitede öğrenim görmektedir. Öğrencilerin yaşlar1 15 ile 24 arasında değişmekte olup yaş ortalaması 18.04 olarak belirlenmiştir. Katılımcıların 432'si (\%66.5) kadın, 217’si (\%33.5) erkektir. 
649 katılımcidan toplanan veriler IBM SPSS Statistics v20.0 programı aracılığıyla tesadüfî bir şekilde ikiye bölünmüş ve iki ayrı veri seti elde edilmiştir. Buna göre, 349 kişi üzerinde açımlayıcı faktör analizi (AFA), 300 kişi üzerinde doğrulayıcı faktör analizi (DFA) işlemleri yapılmıştır.

\section{Veri toplama araçları}

Kişisel Bilgi Formu: Araştırmacılar tarafından hazırlanan Kişisel Bilgi Formu, katılımcıların yaş, cinsiyet gibi bazı demografik bilgilerini almaya dönük soruları içermektedir.

Beden Değeri Ölçeği-2: Tylka ve Wood-Barcalow (2015) tarafından geliştirilen Beden Değeri Ölçeği-2 5'li Likert (1=Asla, 2=Nadiren, 3=Bazen, 4=S1k s1k, 5=Her zaman) türü bir ölçme aracıdır. Ölçme aracı 10 maddeden oluşmakta ve katılımcılardan her bir maddeye katılma oranlarını belirtmeleri istenmektedir. Ölçeğin orijinali için örneklem üniversiteden ve çevrimiçi topluluktan seçilmiş ve 820 kadın ve 767 erkek çalışmaya katılmıştır. Ölçekte ters madde bulunmamakta ve ölçekten en az 10, en fazla 50 puan alınabilmektedir. Ölçekte yer alan maddelerin puanları toplanarak toplam bir puan elde edilmektedir. Ölçekten alınan düşük puan bireylerin olumsuz beden değerine sahip olduğunu, yüksek puan ise olumlu beden değerine sahip olduğunu göstermektedir. Ölçeğin orijinali için hesaplanan iç tutarlılık güvenirlik katsayısı kadınlar için .94, erkekler için .93 olarak bulunmuştur. Test tekrar test yöntemiyle güvenirliğini belirleyebilmek amacıyla ölçek 208 kişiye üç hafta arayla uygulanmıştır. Uygulama sonucunda ölçeğin test tekrar test güvenirlik katsayısı hem kadınlar hem de erkekler için .90 olarak bulunmuştur (Tylka ve Wood-Barcalow, 2015).

\section{İșlem}

Beden Değeri Ölçeği-2'nin uyarlama çalışması için sorumlu yazarlar Tracy L. Tylka ve Nichole L. Wood-Barcalow ile e-posta yoluyla iletişim kurularak izin alınmıştır. Daha sonra ölçek Trabzon Üniversitesi Rehberlik ve Psikolojik Danışmanlık ile Yabancı Diller Eğitimi bölümlerinde görev yapan üç ögretim üyesi tarafından Türkçeye çevrildikten sonra bu Türkçe formların tekrar İngilizceye çevrilmesiyle birlikte iki form arasındaki tutarlılık incelenmiştir. Yapılan çeviriler incelenerek ölçek maddelerine karar verilmiştir (Dil ve kapsam geçerliliği ile ilgili detaylı bilgiler bulgular kısmında verilmiştir). Dil geçerliliği tamamlanan ölçeğin öncelikle anlaşılabilir olmasını test etmek üzere 30 kişi ile pilot çalışması yapılmış ve elde edilen analiz sonuçlarına göre ölçeğe son hali verilmiştir.

Katılımcılar 2018-2019 eğitim öğretim yılları arasında çeşitli okul türlerinde öğrenim gören lise ve üniversite öğrencilerinden oluşturulmuştur. Ölçme araçları öğrencilere ders saatlerinde uygulanmıştır. Öğrencilere çalışmayla ilgili ve kişisel bilgilerinin gizli tutulacağıyla ilgili bilgi verilmiş, daha sonra kişisel bilgi formu ve ölçek formu çalışmaya dâhil olmayı kabul eden öğrencilere uygulanmıştır. Ölçeklerin doldurulması her öğrenci için yaklaşık olarak 10 dakika sürmüştür ve toplam 649 veri elde edilmiştir.

\section{Verilerin analizi}

Bu çalışmada Beden Değeri Ölçeği-2'nin faktör yapısının geçerli bir model olup olmadığının saptanması için açımlayıcı faktör analizi -AFA (exploratory factor analysis) ve doğrulayıcı faktör analizi-DFA (confirmatory factor analysis) yapılmıştır. Bu çalışmada AFA uygulanmasının nedeni Beden Değeri Ölçeği-2'nin orijinal formunun Türk bireyler üzerinde uygulanıp uygulanmayacağını ve Türk bireyler üzerindeki yapısını açığa çıkarmaktır. DFA kullanılmasının nedeni ise Beden Değeri Ölçeği-2'ne yapılan açımlayıcı faktör analizi sonrasında ölçeğin yapısının Türk lise ve üniversite öğrencileri üzerinde doğrulanıp doğrulanmadığını incelemektir. Beden Değeri Ölçeği-2'nin güvenirliği iç tutarlık yöntemiyle incelenmiştir. Ölçeğin geçerlik ve güvenirlik analizleri için IBM SPSS Statistics v20.0 ve Lisrel 8.80 programları kullanılmıştır. 


\section{Bulgular}

\section{Kapsam geçerliliği}

Kapsam geçerliliği çalışması için Davis (1992) tekniğinden yararlanılmıştır. Bu teknik uzman görüşlerini (a) "Uygun", (b) "Madde hafifçe gözden geçirilmeli", (c) "Madde ciddi olarak gözden geçirilmeli" ve (d) "Madde uygun değil" şeklinde dörtlü derecelendirmektedir ve (a) ve (b) seçeneğini işaretleyen uzmanların sayısı toplam uzman sayısına bölünerek, maddeye ilişkin kapsam geçerlik indeksi elde edilmektedir ve 0,80 değeri ölçüt olarak kabul edilmektedir (Yurdugül, 2005). Alandan 10 uzmanın görüşüne başvurularak ölçek maddelerinin kapsam geçerlilik indeksleri elde edilmiştir. 1, 2, 3, 6, 7, 8, 9 ve 10. maddelerin kapsam geçerlilik indeksleri 1.00 olarak, 4.maddenin kapsam geçerlilik indeksi 0,90 olarak bulunmuş ve minimum değerden yüksek olduğu belirlenmiştir. 5. maddenin kapsam geçerlilik indeksi 0,70 olarak bulunmuş, minimum değerden düşük olduğu görülmüş ve madde revize edilmiştir. Revize edilen maddenin dil açısından yetersiz olduğu saptanmış ve madde dil bilgisine uygun olarak düzeltilmiştir. Kapsam geçerliliği sağlandıktan sonra uygulama aşamasına geçilmiştir.

\section{Normallik testi}

Açımlayıcı faktör analiziyle ilgili işlemlere geçilmeden önce örneklemin normal dağılıma uygun olup olmadığı kontrol edilmiş, normallik analizi için çarpıklık ve basıklık değerleri incelenmiştir. Toplam 649 katılımcının cevapları üzerinde toplam puanları alınarak yapılan normallik testi sonucunda çarpıklık ve basıklık katsayılarının (Skewness $=-.47$, Kurtosis $=.31$ ) uygun değerler (Büyüköztürk, 2016) arasında olduğu tespit edilmiştir.

Beden Değeri Ölçeği-2'nin geçerlik çalışması kapsamında ölçme aracının faktör analizi için uygunluğunu tespit edebilmek amaciyla Kaise-Meyer-Olkin (KMO) ve Barlett testleri yapılmıştır. Kaise-Meyer-Olkin (KMO) testi; örneklem büyüklüğü açısından faktör analizi için veri yapısının uygunluğunu test etmenin bir diğer yolu olduğu, ayrıca KMO değerinin yüksek olması ölçekteki her bir değişkenin diğer değişkenler tarafından mükemmel bir şekilde tahmin edilebileceği anlamına geldiği ifade edilmektedir (Çokluk, Şekercioğlu ve Büyüköztürk, 2014). Kaise-Meyer-Olkin $(\mathrm{KMO})=.92$ ve Bartlett testi $\chi 2$ değeri ise 1712,84 $(\mathrm{p}<.001)$ olarak bulunmuştur. KMO'nun .60'dan yüksek, Bartlett testinin de anlamlı çıkması verilerin faktör analizi için uygun olduğunu ve örneklem büyüklüğünün yeterli olduğunu gösterir (Büyüköztürk, 2016).

\section{Açımlayıcı faktör analizi (AFA)}

Açımlayıcı faktör analizinde ilk olarak korelasyon matrisi tablosu incelenmiştir. Ölçek maddeleri arasındaki korelasyon katsayıları Tablo 1'de sunulmuştur. Ölçek maddeleri arasındaki korelasyon katsayılarının .30 ile .80 arasında değişmesi gerektiği bilgisinden hareketle tüm maddelerin bu aralıkta olduğu görülmüştür.

Tablo 1.

Ölçek Maddeleri Arasındaki Korelasyon Katsayıları

\begin{tabular}{rllllllllll}
\hline & 1 & 2 & 3 & 4 & 5 & 6 & 7 & 8 & 9 & 10 \\
\hline Korelasyon1 & 1 & & & & & & & & & \\
2 & .68 & 1 & & & & & & & & \\
3 & .44 & .56 & 1 & & & & & & & \\
4 & .65 & .72 & .59 & 1 & & & & & & \\
5 & .40 & .41 & .37 & .43 & 1 & & & & & \\
6 & .51 & .66 & .45 & .63 & .39 & 1 & & & & \\
7 & .41 & .43 & .51 & .44 & .34 & .55 & 1 & & & \\
8 & .34 & .41 & .38 & .34 & .40 & .43 & .47 & 1 & & \\
9 & .55 & .67 & .58 & .64 & .41 & .65 & .49 & .42 & 1 & \\
10 & .44 & .52 & .50 & .48 & .29 & .51 & .54 & .44 & .50 & 1 \\
\hline
\end{tabular}


Açımlayıcı faktör analizi kapsamında temel bileşenler analizi yapılmıştır. Yapılan analiz sonucunda elde edilen bulgularda ölçeğin 1 değerinden büyük olan bir öz değer bulunmuş ve öz değeri 5.45 olan toplam varyansın \% 49.8'ini açıklayan tek faktörlü bir yapı elde edilmiştir. Açımlayıcı faktör analizi kapsamında madde faktör yük değerlerinin incelenmesi için yamaç birikinti grafiği incelenmiştir ve Şekil 1'de gösterilmiştir. Öz değere ait çizgi grafiğinin de tek boyutluluğu işaret ettiği görülmektedir ve bu varsayımı test etmek için tüm maddeler tek faktöre sınırlandırılmıştır (Kuzucu, 2008).

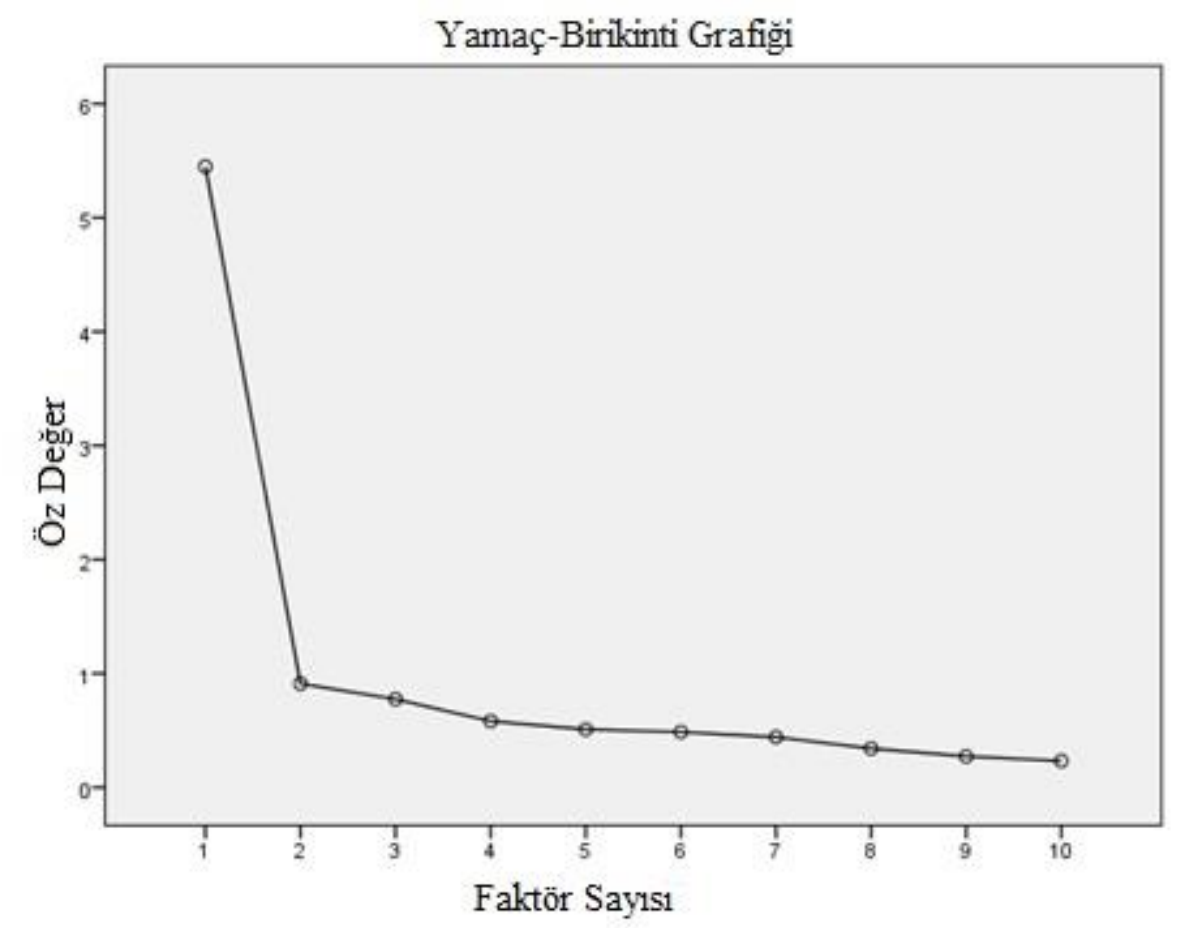

Şekil 1. Yamaç-Birikinti Grafiği (Scree plot)

Ölçeğin faktör yükleri .53 ile .83 arasında değişmektedir. Açımlayıcı faktör analizi sonucunda elde edilen bulgular ve ölçeğe ilişkin faktör yükleri Tablo 2'de verilmiştir.

Tablo 2.

Beden Değeri Ölçeği-2'nin Madde Faktör

Yük Değerleri ve Açıkladığı Varyans Miktarı

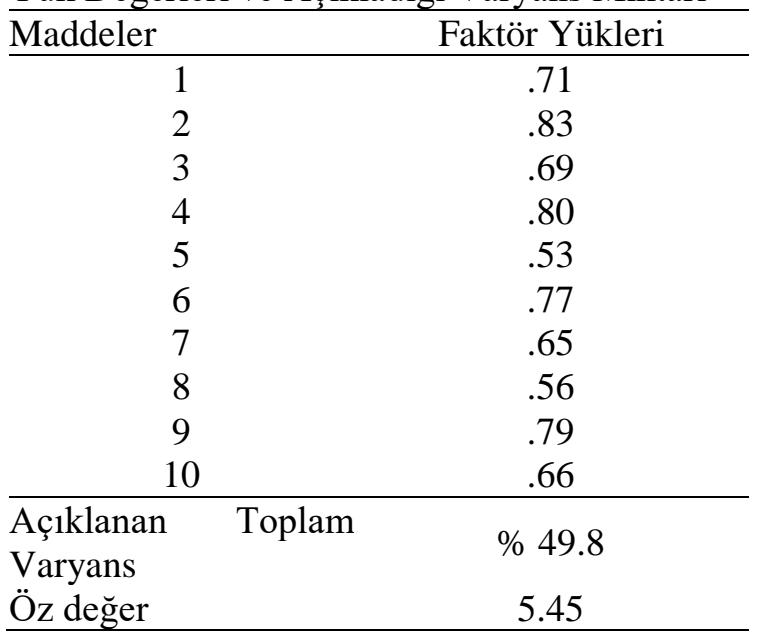


Ölçeğin toplam açıklanan varyans değeri \%49.8 olarak bulunmuştur. Tek faktörlü ölçeklerde açıklanan varyans oranının $\% 30$ ve daha fazla olması yeterli görülmekte, çok faktörlü ölçekler için varyans miktarının daha fazla olması istenmektedir (Büyüköztürk, 2016). Açımlayıcı faktör analizini değerlendirilirken öz değeri birden büyük faktörlerin ele alınmasına, değişkenlerin faktör içerisindeki ağırlığını gösteren faktör yüklerinin yüksek olmasına dikkat edilmiştir. Bu doğrultuda araştırma sürecinde açımlayıcı faktör analizi sonucunda elde edilen \%49.8 varyans değerinin ölçeğin faktör yapısına karar vermede yeterli olduğu görülmüştür.

\section{Doğrulayıcı faktör analizi (DFA)}

Beden Değeri Ölçeği-2 için yapılan açımlayıcı faktör analizi sonrasında belirlenen yapının doğrulanıp doğrulanmadığını ortaya koymak amacıyla Doğrulayıcı Faktör Analizi (DFA) yapılmıştır. Analiz, tek faktörlü yapı olarak 300 lise ve üniversite öğrencisi üzerinde gerçekleştirilmiştir. DFA sonuçlarına genel olarak bakıldığında, $\chi 2=131.97$ ve serbestlik derecesi=35 ve ki-karenin serbestlik derecesine oranının 3'ün üstünde olduğu, RMSEA indeksinin (.096) 0.08'in üstünde olduğu, standardize edilmiş RMR'nin 0.062 olduğu, NFI ve CFI indekslerinin 0.90'ın üzerinde olduğu ve yapılan analizler incelendiğinde bazı maddeler arasında modifikasyon (düzeltme) istendiği görülmüştür.

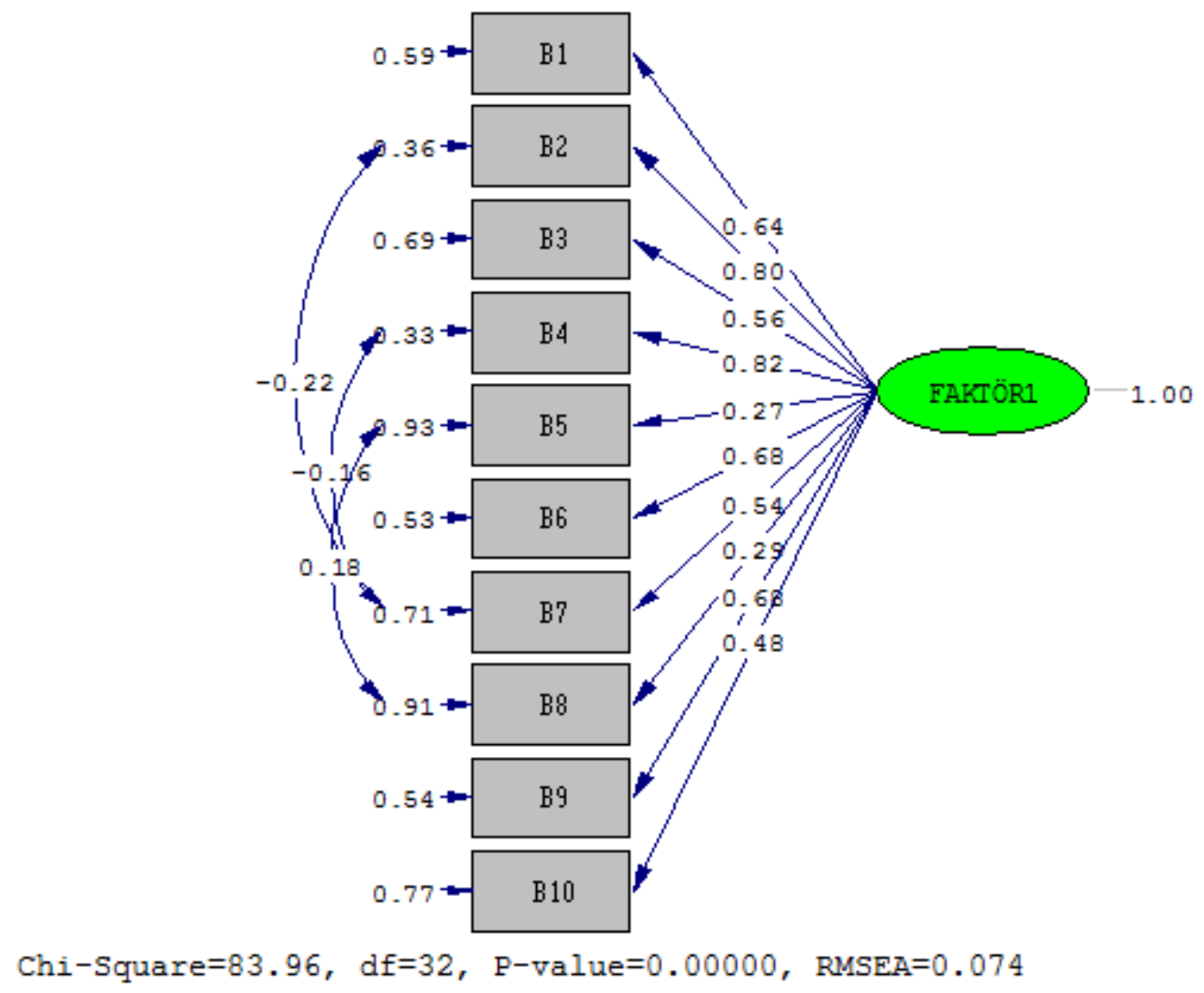

Şekil 2. Beden Değeri Ölçeğii-2’ne Yönelik Path Diyagramı

Önerilen modifikasyonların madde 2 ile madde 7, madde 4 ile madde 7 ve madde 5 ile madde 8 arasında olduğu gözlenmiştir. Kurulan modeli iyileştirmek amacıyla programın önerdiği düzeltmeler uzman görüşü alınarak yapılmıştır. Yapılan modifikasyon sonrasında model uyum indeksleri $(\chi 2$ : 83.96; sd: $32, \chi 2$ sd: 2.62, NFI: .95, CFI: .97, IFI=0.97, RFI=0.93, GFI=0.95, AGFI=0.91, RMSEA: .074, SRMR: .049) olarak bulunmuştur. Bu uyum indeksi değerleri modelin uyumlu olduğunu ortaya koymaktadır. Tüm bu sonuçlar birlikte değerlendirildiğinde ölçeğin yapı geçerliliğini sağladığı ve geçerli ve güvenilir bir araç olduğu doğrulanmaktadır. 


\section{Güvenirlik analizi}

Beden Değeri Ölçeği-2'nin güvenirlik analizlerinde Cronbach alfa iç tutarlık katsayısı tekniğinden faydalanılmıştır. Ölçekte yer alan her bir madde için madde ortalamaları, standart sapmaları, madde-toplam korelasyonları ve maddelerin tamamına ilişkin Cronbach alfa güvenirlik katsayıları Tablo 3'te sunulmuştur.

Tablo 3.

Beden Değeri Ölçeği-2’ne İlişkin Ortalama, Standart Sapma, Madde Toplam Korelasyonları Değerleri

\begin{tabular}{ccccc}
\hline Maddeler & $\bar{X}$ & SS & $\begin{array}{c}\text { Madde Toplam } \\
\text { Korelasyonu }\end{array}$ & $\begin{array}{c}\text { Madde Çıkarıldığında } \\
\text { Cronbach Alpha Güvenirlik } \\
\text { Katsayı1s }\end{array}$ \\
\hline 1 & 4.28 & .87 & .66 & .89 \\
2 & 3.83 & .98 & .77 & .89 \\
3 & 4.13 & .94 & .66 & .89 \\
4 & 3.99 & .98 & .74 & .89 \\
5 & 4.25 & .87 & .50 & .90 \\
6 & 2.93 & 1.29 & .73 & .89 \\
7 & 3.75 & 1.07 & .63 & .90 \\
8 & 3.85 & 1.03 & .54 & .90 \\
9 & 3.82 & 1.06 & .75 & .89 \\
10 & 3.57 & 1.22 & .64 & .90 \\
\hline
\end{tabular}

Ölçeğin güvenirlik analizleri incelendiğinde; genel güvenirliği .90 olarak bulunmuştur. Ölçeği oluşturan faktörlerin güvenirlik katsayılarının ve açıklanan varyans oranlarının yüksek olması ölçeğin güçlü bir faktör yapısına ve tatmin edici düzeyde güvenirliğe sahip olduğunu göstermektedir.

\section{Tartışma}

Bu çalışmada Tylka ve Wood-Barcalow (2015) tarafından geliştirilmiş olan BAS-2'nin Türkçeye uyarlanması, Türkçe formun geçerlik ve güvenirliğinin incelenmesi amaçlanmıştır. Ölçeğin orijinal formunun faktör yapısının Türk kültüründe de geçerli olup olmadığını test etmek üzere açımlayıcı faktör analizi (AFA) yapılmıştır (Orçan, 2018) ve elde edilen sonuçlara göre toplam varyansın \% 49.8'ini açıklayan tek faktörlü bir yapı elde edilmiştir. Tek faktörlü ölçeklerde açıklanan varyans oranının \%30 ve daha fazla olması yeterli görülmekte, çok faktörlü ölçekler için varyans miktarının daha fazla olması istenmektedir (Büyüköztürk, 2016). Özgün formun faktör yapısının Türk lise ve üniversite öğrencilerinden oluşan örneklemde doğrulanıp doğrulanmayacağını belirlemek üzere doğrulayıcı faktör analizi (DFA) yapılmıştır (Orçan, 2018). DFA için uyum indeksi sinırları göz önüne alındığında (Hu ve Bentler, 1999), modelin uyumlu olduğu ortaya koyulmuştur. Araştırmalarda kullanılabilecek ölçme araçları için öngörülen güvenirlik düzeyinin .70 olduğu (Tezbaşaran, 1996) dikkate alınırsa, ölçeğin tatmin edici düzeyde güvenirliğe sahip olduğu belirtilebilir.

Yapılan madde analizi sonucunda ölçeğin madde-toplam korelasyon katsayılarının .30 ölçütünü (Büyüköztürk, Akgün, Kahveci ve Demirel, 2004) karşıladığı ve madde toplam korelasyon katsayılarının yüksek düzeyde olduğu görülmektedir. Geçerlik ve güvenirlik çalışmalarından elde edilen bulgulara göre ölçeğin kullanıma hazır olduğu belirtilebilir. Beden Değeri Ölçeği-2 uygulanması ve değerlendirmesi kolay, pratik bir öz-bildirim tarzı ölçektir. Ölçeğin psikometrik özelliklerini Türk lise ve üniversite öğrencilerinde incelemeye yönelik bu çalışmada orijinal ölçekle benzer sonuçlara ulaşılmıştır. Gerek açımlayıcı gerekse doğrulayıcı faktör analizi sonuçları ölçeğin yapı geçerliği açısından özgün formuyla paralel olduğunu göstermiştir. Geçerlik ve güvenirlik çalışması sonucu elde edilen bulgular, ölçeğin beden değerini ölçebilmek için yeterli düzeyde geçerlik ve güvenirliğe sahip olduğunu ortaya koymuştur. Diğer 
yandan BAS-2'nin Anlı ve diğerleri (2015) tarafından Türkiye örnekleminde uyarlama çalışması yapılmış ve benzer sonuçlar elde edilmiştir. Ancak çalışma grubu farklılığ çalışmasında AFA ölçümlerinin yapılmamış olması ve bu durumun literatür için bir sınırlılık değil zenginlik olarak değerlendirilmesi bu çalışma için motivasyon kaynağı olmuştur.

Çeşitli nedenlerle görselliğin ve estetiğin yüceltildiği ve son derece önemli anlamlar yüklenildiği günümüz dünyasında, beden imajına ve beden değerine dikkatin yoğunlaştığ 1 gözlenmektedir. $\mathrm{Bu}$ durumun bireysel yansımalarına bakıldığında beden imajı ve beden değerinin özellikle dönemsel olarak bedenleri ile daha çok ilgili olan ergen ve genç yetişkinler için önemli olduğu ve gerçekçi olmayan değerlendirme ve beklentilere neden olduğu düşünülmektedir. Bu gerekçeler beden imajı ve beden değeri ile ilgili çalışmaların arttırılması için önemli bir neden olarak görülmüş, bu bağlamda çalışmanın beden imajı ile ilgili literatüre katkı sağlaması umut edilmektedir.

\section{Kaynaklar}

Anlı, G., Akın, A., Eker, H. ve Özçelik, B. (2015). Bedeni Beğenme Ölçeği: Geçerlik ve güvenirlik çalışması. The Journal of Academic Social Science Studies, 36, Summer II, 505-511.

Avalos, L. C. ve Tylka, T. L. (2006). Exploring a model of intuitive eating with college women. Journal of Counseling Psychology, 53, 486-497.

Avalos, L. C., Tylka, T. L. ve Wood-Barcalow, N. (2005). The Body Appreciation Scale: Development and psychometric evaluation. Body Image, 2, 285-297.

Barlett, C. P. ve Harris, R. J. (2008). The impact of body emphasizing video games on body image concerns in men and women. Sex Roles, 59, 586-601.

Bergeron, D. ve Tylka, T. L. (2007). Support for the uniqueness of body dissatisfaction from drive for muscularity among men. Body Image, 4(3), 288-295.

Büyüköztürk, Ş. (2016). Sosyal bilimler için veri analizi el kitabı: Istatistik, araştırma deseni, SPSS uygulamalarl ve yorum (22. baskl). Ankara: Pegem Akademi.

Büyüköztürk, Ş., Akgün, Ö. E., Kahveci, Ö. ve Demirel, F. (2004). Güdülenme ve öğrenme stratejileri ölçeğinin Türkçe formunun geçerlik ve güvenirlik çalışması. Kuram ve Uygulamada Ĕgitim Bilimleri, 4(2), 207-239.

Cash, T. ve Pruzinsky, T. (2002). Body image: A handbook of theory, research, and clinical practice. Guilford Press, New York.

Çokluk, Ö., Şekercioğlu, G. ve Büyüköztürk, Ş. (2014). Sosyal bilimler için çok değişkenli istatistik: SPSS ve LISREL uygulamalart. Ankara: Pegem Akademi.

Dittmar, H., Halliwell, E. ve Ive, S. (2006). Does Barbie make girls want to be thin? The effect of experimental exposure to images of dolls on the body image of 5-to 8-year old girls. Developmental psychology, 42(2), 283-292.

Hu, L. T. ve Bentler, P. M. (1999). Cut-off criteria for fit indexes in covariance structure analysis: Conventional criteria versus new alternatives. Structural Equation Modeling, 6, 1-55.

Iannantuono, A. C. ve Tylka, T. L.(2012). Interpersonal and intrapersonal links to body appreciation in college women: An exploratory model. Body Image, 9, 227-235.

Joiner, G. W. ve Kashubeck, S. (1996). Acculturation, body image, self-esteem, and eatingdisorder symptomatology in adolescent Mexican American women. Psychology of Women Quarterly, 20(3), 419-435.

Kuzucu, Y. (2008). Duygusal farkındalık düzeyi ölçeğinin uyarlanması: Geçerlik ve güvenirlik çalışmaları. Türk Psikolojik Danışma ve Rehberlik Dergisi, 3(29), 51-64.

Morrison, T. G., Morrison, M. A., Hopkins, C. ve Rowan, E. T. (2004). Muscle mania: Development of a new scale examining the drive for muscularity in Canadian males. Psychology of Men and Masculinity, 5, 30-39.

Oktan, V. ve Şahin, M. (2010). Kız ergenlerde beden imajı ile benlik saygısı arasındaki ilişkinin incelenmesi. Uluslararası Insan Bilimleri Dergisi, 7(2), 553-556.

Orçan, F. (2018). Açımlayıcı ve doğrulayıcı faktör analizi: İlk hangisi kullanılmalı? Eğitimde ve Psikolojide Ölçme ve Değerlendirme Dergisi, 9(4), 413-421. 
Swami, V., Hadji-Michael, M. ve Furnham, A. (2008). Personality and individual difference correlates of positive body image. Body Image, 5, 322-325.

Swami, V., Hwang, C. S. ve Jung, J. (2012). An examination of the factor structure and correlates of acceptance of cosmetic surgery among South Korean university students. Aesthetic Surgery Journal, 32, 220-229.

Swami, V., Stieger, S., Haubner, T. ve Voracek, M. (2008). German translation and psychometric evaluation ofthe Body Appreciation Scale. Body Image, 5, 122-127.

Tezbaşaran, A. A. (1996) Likert tipi ölçek gelişstirme kılavuzu. Ankara: Türk Psikologlar Derneği Yayınları.

Tylka, T. L. ve Kroon Van Diest, A. M. (2013). The Intuitive Eating Scale-2: Item refinement and psychometric evaluation with college women and men. Journal of Counseling Psychology, 60, 137-153.

Tylka, T. L. ve Wood-Barcalow, N. L. (2015). The Body Appreciation Scale-2: item refinement and psychometric evaluation. Body Image, 12, 53-67.

Williams, E. F., Cash, T. F. ve Santos, M. T. (2004). Positive and negative body image: Precursors, correlates, and consequences. 38th Annual Association for the Advancement of Behavior Therapy, New Orleans, LA, 18-21 November.

Yurdugül, H. (2005). Ölçek geliştirme çalışmalarında kapsam geçerliği için kapsam geçerlik indekslerinin kullanılması. XIV. Ulusal Ĕ̈itim Bilimleri Kongresi, Pamukkale Üniversitesi Eğitim Fakültesi, 28-30 Eylül 2005, Denizli.

\section{Extended Abstract}

\section{Introduction}

Body image is the multi-dimensional and complex definition of the individual's thoughts and feelings about body satisfaction, body appreciation and physical condition (Cash \& Pruzinsky, 2002). The physical appearance is an important aspect of the individual's self-perception (Dittmar, Halliwell \& Ive, 2006). Body image consists of many components such as body satisfaction, body appreciation and physical appearance and these components vary from positive to negative. However, it is seen that the body image literature focuses primarily on measuring individuals' adoption of a negative orientation towards themselves (Tylka \& Wood-Barcalow, 2015).

The Body Appreciation Scale-2, developed by Tylka and Wood-Barcalow (2015) was considered important both for focusing on positive body appreciation and for measuring the body appreciation of men and women, and it was thought that the Turkish adaptation study would contribute to the researchers.

BAS-2 was used by researchers to understand the characteristics, correlations and potential consequences of positive body image. BAS-2 is a 5-point Likert type consisting of 10 items and it is applied to adolescents and adults.

The aim of this study was to investigate the validity and reliability of BAS-2 developed by Tylka and Wood-Barcalow (2015) in the Turkish sample. In the study, the hypothesis that the Turkish version of the scale had similar psychometric properties to the original English version was tested. The existence of a very limited number of measurement tools for measuring body image and appreciation in our country has been a source of motivation for conducting the study. This study is thought to fill an important gap in the Turkey literature about body image and appreciation.

\section{Method}

This study was conducted on 649 high school and university students in Trabzon. 285 of these students are in high school and 364 of them are in university. The ages of the students ranged between 15 and 24 and the average age was determined as 18.04. $432(66.5 \%)$ of the participants were female and $217(33.5 \%)$ were male. The data collected from 649 participants were randomly divided into two through the SPSS program and two separate data sets were obtained. Accordingly, exploratory factor analysis was performed on 349 people and confirmatory factor 
analysis was performed on 300 people. Personal information form and Body Appreciation Scale2 prepared by the researchers were used in the data collection. IBM SPSS Statistics v20.0 and Lisrel 8.80 were used for the validity and reliability analyzes of the scale.

\section{Result and Discussion}

In this study, it was aimed to adapt BAS-2 which was developed by Tylka and Wood-Barcalow (2015) into Turkish and to examine the validity and reliability of the Turkish form. The content validity indexes of the scale items were obtained by consulting 10 experts. The content validity index of items $1,2,3,6,7,8,9$ and 10 was found to be 1.00 , and the content validity index of item 4 was found to be 0.90 and it was determined that it was higher than the minimum value. The content validity index of item 5 was found to be 0.70 , it was found to be less than the minimum value and the item was revised. After the content validity was achieved, the implementation phase was started.

In order to test whether the factor structure of the original form of the scale was valid in Turkish culture, exploratory factor analysis (EFA) was conducted (Orçan, 2018) and according to the results, a single factor structure explaining $49.8 \%$ of the total variance was obtained. It is considered sufficient that the variance ratio explained in single factor scales is $30 \%$ and more and the amount of variance is desired for multi-factor scales (Büyüköztürk, 2016). Confirmatory factor analysis (CFA) was used to determine whether the factor structure of the original form was validated in a sample of Turkish high school and university students (Orçan, 2018). Considering the limits of compliance index for DFA (Hu \& Bentler, 1999), the model was found to be compatible. When the reliability analyzes of the scale were examined, the overall reliability was found to be .90 . Considering that the reliability level predicted for the measurement tools that can be used in the research is .70 (Tezbaşaran, 1996), it can be stated that the scale has a satisfactory level of reliability.

As a result of item analysis, item-total correlation coefficients of the scale met .30 criteria (Büyüköztürk, Akgün, Kahveci \& Demirel, 2004) and item-total correlation coefficients were found to be high. According to the findings obtained from the validity and reliability studies, it can be stated that the scale is ready to use. Body Appreciation Scale-2 is a practical self-report style scale that is easy to implement and evaluate. In this study aimed to examine the psychometric properties of the scale in Turkish high school and university students, similar results were obtained with the original scale. The results of both exploratory and confirmatory factor analysis showed that the scale was in parallel with its original form in terms of construct validity. The results obtained from the validity and reliability study showed that the scale had sufficient validity and reliability to measure the body appreciation. 